\title{
COPD and cardiovascular diseases: now is the time for action!
}

\author{
Fernando Sergio Leitao Filho, ${ }^{1,2}$ Don D $\operatorname{Sin}^{1,2}$
}

Cardiovascular disease (CVD) is the leading cause of mortality worldwide, responsible for $31 \%$ of all deaths and accounting for 18 million deaths annually. ${ }^{1}$ Chronic obstructive pulmonary disease (COPD), which is characterised by airflow limitation that is usually progressive and associated with persistent small airway inflammation, is an important (though frequently under-recognised) risk factor for CVDs. ${ }^{2}$ For example, the population attributable risk of COPD for mortality related to ischaemic heart disease is approximately 30\%, independent of the effects of cigarette smoking. ${ }^{3}$ Indeed, some studies have shown that the risk imposed by COPD for CVDs may be as large as (if not larger than) those related to well-established CVD risk factors such as hypertension and hypercholesterolaemia. ${ }^{3}$ A more recent study showed that COPD is associated with increased risk of sudden cardiac deaths, with the risk increasing by more than threefold among patients with COPD who have a history of frequent exacerbations. ${ }^{4}$

In this issue of Thorax, Morgan and colleagues extend our current understanding of the relationship between COPD and CVDs by demonstrating that COPD is a significant risk factor for 12 different CVD conditions including angina, myocardial infarction (MI), heart failure, sudden cardiac arrest, atrial fibrillation, abdominal aortic aneurysm, peripheral arterial disease, pulmonary arterial hypertension, ischaemic stroke, haemorrhagic stroke and transient ischaemic attacks. ${ }^{5}$ Most importantly, they showed that the highest risks were observed among relatively young individuals with COPD (aged 35-54 years) with HRs related to these CVD outcomes ranging between 3 and 7 . These findings are somewhat unexpected given that both COPD and CVDs are diseases of ageing and senescence (if we were to assume that this relationship was by chance or confounded by ageing). The strengths of this study include the

\footnotetext{
${ }^{1}$ Centre for Heart Lung Innovation, St. Paul's Hospital, Vancouver, British Columbia, Canada

${ }^{2}$ Division of Respiratory Medicine, Department of Medicine, University of British Columbia, Vancouver, British Columbia, Canada
}

Correspondence to Dr Don D Sin, Centre for Heart Lung Innovation, St Paul's Hospital, Vancouver, BC V6Z 1Y6, Canada; don.sin@hli.ubc.ca large sample size $(n=209$ 909), a robust inclusion of female patients (representing nearly $50 \%$ of the cohort), a good representation of age categories above and below the mean age of 65 years and a nice mix of current and ex-smokers (1:1 ratio). In addition, the authors fully captured the 12 CVD outcomes (noted previously) during follow-up, ensuring confidence in the integrity of the 'exposure' and 'outcome' variables of this study. The authors also used a validated algorithm to identify patients with COPD in this cohort, providing additional assurance of the study design. Interestingly, 2.6\% of the COPD cases included in this analysis were never smokers, similar to other reports, ${ }^{6}$ which raises the possibility that these individuals had other risk factors such as asthma, childhood respiratory illness or exposure to passive smoke or biomass fuel (though this information was not available in this study).

There were some limitations, however, that should be highlighted. Notably, cigarette smoking status (expressed as never, ex and current), which is the most important shared risk factor for COPD and CVDs, was only ascertained at the date closest to the COPD diagnosis. Further, objective measurements of smoking such as those that would detect salivary or urinary cotinine levels or exhaled carbon monoxide concentrations were not used ${ }^{7}$ and, in $9 \%$ of the cohort, smoking status information was completely missing. Due to these factors, the HRs for each CVD outcome were adjusted only for gender and general practitioner practice. To address the possibility of confounding by smoking, the authors carried on a sensitivity analysis, recoding patients with COPD with smoking missing data as ex-smokers, and obtained similar results. The HRs were also not 'corrected' for other shared risk factors (and thus potential confounders) including hypertension, hypercholesterolaemia, secondhand smoke exposure, air pollution, abdominal obesity or family history of CVDs. Moreover, there was no information on COPD exacerbations, which are important lifeevents (usually precipitated by respiratory tract infections) that increase the risk of cardiovascular events including MI and stroke by twofold to threefold. ${ }^{8}$

Notwithstanding these limitations, the results from Morgan et al add to the growing body of evidence that COPD, independent of cigarette smoking and other shared risk factors, is causally related to CVD. ${ }^{5}$ While the exact mechanisms have not been fully elucidated, there are some interesting (non-mutually exclusive) pathways that have been recently unravelled. First, COPD is associated with persistent lung inflammation, which may 'spill over' into the systemic circulation, contributing to endothelial injury and dysfunction and promoting atherosclerosis over time. ${ }^{9}$ Second, patients with COPD are at increased risk of viral and bacterial respiratory tract infections, leading to exacerbations. Exacerbations, in turn, increase the risk of acute cardiovascular events. A recent study by Kwong et al showed that acute respiratory tract infection related to influenza $B$ increased the risk of MI by 10 -fold. ${ }^{10}$ The incidence ratio of MI related to influenza A, respiratory syncytial virus and other viruses was 5, 4 and 3, respectively, compared with that during control (ie, non-infectious) periods. In a murine model, Jaw and colleagues showed that acute respiratory tract infection converts 'stable' atherosclerotic plaques into vulnerable ones (and to plaque rupture) within 24 hours of the infection. Interestingly, this process could be averted by depleting (or inhibiting) neutrophilic inflammation related to the respiratory tract infection. ${ }^{11}$ Third, COPD is associated with increased risk of ventricular arrhythmias, ${ }^{12}$ which is a major risk for sudden cardiac death. Hypoxia (which typically worsens during exacerbations), electrocardiographic abnormalities (such as bundle branch block), ${ }^{13}$ myocardial ischaemia ${ }^{8}$ and right ventricular remodelling (due to pulmonary hypertension) ${ }^{14}$ are some of the key factors related to this proarrhythmic status observed in COPD. Together, these and other data indicate that patients with COPD are at high risk of CVDs and death related to CVDs, especially during periods of exacerbations.

What are the clinical implications of the study results by Morgan et al for the practicing physicians? First, it is very important to assess the underlying cardiovascular risk of patients with COPD using a well-established clinical tool such as the Framingham Risk Calculator or others and implement lifestyle modifications and appropriate pharmacological interventions, where necessary, when the risk is deemed unacceptably high. ${ }^{15}$ Second, patients with COPD should receive yearly influenza vaccination (which has been unequivocally shown to reduce the risk of cardiovascular events). ${ }^{16}$ Third, for patients in the Global Initiative for Chronic Obstructive Lung 
Disease (GOLD) assessment category ' $\mathrm{C}$ ' or 'D' (ie, frequent exacerbators), aggressive therapies should be implemented to reduce the risk of exacerbations. ${ }^{2}$ Inhaled bronchodilators (with or without inhaled corticosteroids) are generally safe and may in some cases reduce the risk of poor cardiovascular outcomes. ${ }^{17}$ In $2015,50 \%$ of the global deaths were attributed to CVD or respiratory diseases such as COPD. ${ }^{18} \mathrm{CVDs}$ and COPD are both preventable and treatable. Now is the time for chest physicians, cardiologists and primary care providers to work hand in hand to implement the best management solutions to produce the best results for our patients with COPD. COPD can be defeated but only if we treat the whole person in front of us and not just their lung disease.

Contributors Both authors contributed equally to this editorial.

Funding The authors have not declared a specific grant for this research from any funding agency in the public, commercial or not-for-profit sectors.

Competing interests DDS holds a Tier 1 Canada Research Chair in COPD.

Patient consent Not required.

Provenance and peer review Commissioned; internally peer reviewed.

(c) Article author(s) (or their employer(s) unless otherwise stated in the text of the article) 2018. All rights reserved. No commercial use is permitted unless otherwise expressly granted.

D) Check for updates
To cite Leitao Filho FS, Sin DD. Thorax 2018;73:799-800.

Accepted 26 March 2018

Published Online First 5 April 2018

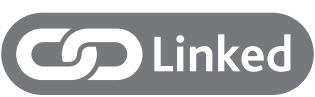

- http://dx.doi.org/10.1136/thoraxjnl-2017-210865

Thorax 2018;73:799-800.

doi:10.1136/thoraxjnl-2018-211553

\section{REFERENCES}

1 GBD 2016 Causes of Death Collaborators. Global, regional, and national age-sex specific mortality for 264 causes of death, 1980-2016: a systematic analysis for the Global Burden of Disease Study 2016. Lancet 2017:390:1151-210.

2 Vogelmeier CF, Criner GJ, Martinez FJ, et al. Global strategy for the diagnosis, management, and prevention of chronic obstructive lung disease 2017 report. GOLD executive summary. Am J Respir Crit Care Med 2017; 195:557-82.

3 Hole DJ, Watt GC, Davey-Smith G, et al. Impaired lung function and mortality risk in men and women: findings from the Renfrew and Paisley prospective population study. BMJ 1996;313:711-5. discussion 15-6.

4 Lahousse L, Niemeijer MN, van den Berg ME, et al. Chronic obstructive pulmonary disease and sudden cardiac death: the Rotterdam study. Eur Heart J 2015;36:1754-61.

5 Morgan AD, Rothnie KJ, Bhaskaran K, et al. Chronic obstructive pulmonary disease and the risk of 12 cardiovascular diseases: a populationbased study using UK primary care data. Thorax 2018:thoraxjnl-2017-210865.

6 Tan WC, Sin DD, Bourbeau J, et al. Characteristics of COPD in never-smokers and ever-smokers in the general population: results from the CanCOLD study. Thorax 2015;70:822-9.
7 Obeidat M, Ding X, Fishbane N, et al. The effect of different case definitions of current smoking on the discovery of smoking-related blood gene expression signatures in chronic obstructive pulmonary disease. Nicotine Tob Res 2016;18:1903-9.

8 Donaldson GC, Hurst JR, Smith CJ, et al. Increased risk of myocardial infarction and stroke following exacerbation of COPD. Chest 2010;137:1091-7.

9 Van Eeden S, Leipsic J, Paul Man SF, et al. The relationship between lung inflammation and cardiovascular disease. Am J Respir Crit Care Med 2012;186:11-16.

10 Kwong JC, Schwartz KL, Campitelli MA, et al. Acute myocardial infarction after laboratoryconfirmed influenza infection. N Eng/ J Med 2018;378:345-53.

11 Jaw JE, Tsuruta M, Oh Y, et al. Lung exposure to lipopolysaccharide causes atherosclerotic plaque destabilisation. Eur Respir J 2016;48:205-15.

12 Yildiz P, Tükek T, Akkaya V, et al. Ventricular arrhythmias in patients with COPD are associated with QT dispersion. Chest 2002;122:2055-61.

13 Warnier MJ, Rutten FH, Numans ME, et al. Electrocardiographic characteristics of patients with chronic obstructive pulmonary disease. COPD 2013;10:62-71.

14 Weir-McCall JR, Liu-Shiu-Cheong PS, Struthers AD, et al. Pulmonary arterial stiffening in COPD and its implications for right ventricular remodelling. Eur Radiol 2018;28:3464-72.

15 Lee HM, Lee J, Lee K, et al. Relation between COPD severity and global cardiovascular risk in US adults. Chest 2012;142:1118-25.

16 Phrommintikul A, Kuanprasert S, Wongcharoen W, et al. Influenza vaccination reduces cardiovascular events in patients with acute coronary syndrome. Eur Heart J 2011;32:1730-5.

17 Tashkin DP, Celli B, Senn S, et al. A 4-year trial of tiotropium in chronic obstructive pulmonary disease. $N$ Engl J Med 2008;359:1543-54.

18 Prabhakaran D, Anand S, Watkins D, et al. Cardiovascular, respiratory, and related disorders: key messages from Disease Control Priorities, 3rd edition. Lancet 2018;391:1224-36. 